The University of San Francisco

USF Scholarship: a digital repository @ Gleeson Library |

Geschke Center

Kinesiology (Formerly Exercise and Sport Science)

College of Arts and Sciences

$8-2007$

\title{
Do Fans Want Close Contests? A Test of the Uncertainty of Outcome Hypothesis in the National Basketball Association
}

Daniel A. Rascher

University of San Francisco, RASCHER@USFCA.EDU

John Paul G. Solmes

Follow this and additional works at: http://repository.usfca.edu/ess

Part of the Sports Management Commons

\section{Recommended Citation}

Rascher, Daniel A. and Solmes, John Paul G., "Do Fans Want Close Contests? A Test of the Uncertainty of Outcome Hypothesis in the National Basketball Association" (2007). Kinesiology (Formerly Exercise and Sport Science). Paper 5.

http://repository.usfca.edu/ess/5

This Article is brought to you for free and open access by the College of Arts and Sciences at USF Scholarship: a digital repository @ Gleeson Library | Geschke Center. It has been accepted for inclusion in Kinesiology (Formerly Exercise and Sport Science) by an authorized administrator of USF Scholarship: a digital repository@ Gleeson Library | Geschke Center. For more information, please contact repository@usfca.edu. 


\section{Do Fans Want Close Contests?}

A Test of the Uncertainty of Outcome Hypothesis in the National Basketball Association

Daniel A. Rascher ${ }^{1}$ and John Paul G. Solmes ${ }^{2}$

'University of San Francisco

${ }^{2}$ KPMG LLP

Daniel A. Rascher, $\mathrm{PhD}$, is the director of academic programs and an associate professor in the sport management program. His research interests include sport economics and sport finance.

John Paul G. Solmes is an accountant with KPMG LLP in Toronto, Canada, and a graduate of Queen's University. His research interests include sport economics and the NBA.

\section{Abstract}

The National Basketball Association claims to sell entertainment. Part of that entertainment is close, competitive contests with uncertain outcomes. However, hometown fans want the home team to win. Hence, the optimal probability that the home team wins a game, from the perspective of maximizing demand, lays somewhere between 0.5 and 1.0 . Using data from individual games for the 2001-02 season, this optimal probability was estimated to be approximately 0.66. Fans want their home team to have about twice the chance to win a game as the visiting team.

Keywords: uncertainty of outcome, basketball, linear regression, home court advantage, demand, attendance

\section{Introduction}

Competitive balance is an important feature of sports leagues. If the outcome of a contest or a season is nearly certain, demand may begin to decline. Competitive balance can refer to the season-long race between teams for a league title or the closeness or uncertainty of each contest. As pointed out by Fort and Quirk (1992), competitive balance can also refer to the variation in champions from season to season. Further, competitive balance could refer to the closeness of a contest within the game itself, i.e., is the outcome of the game uncertain all the way up to the end of the game or has it been decided early on? If uncertainty of each game is important to cus- tomers, then the ex ante probability that the home team wins a particular game should be about 0.5 in order to maximize sales (e.g., attendance at sporting events or viewership on television). On the other hand, if fans want the home team to prevail in a particular contest, then the optimal ex ante probability that the home team will win should approach 1.0. If both of these components of demand are true, then the optimal probability will lay somewhere between 0.5 and 1.0.

In aggregate, there are as many wins in a season as there are losses. However, in order to increase fan enjoyment and maximize league revenue, each team should win more often at home. Therefore, it is optimal for leagues to attempt to maintain competitive balance throughout 
the season and concurrently have home teams win more often.

Can sport managers influence the desired home court advantage needed to produce a probability between 0.5 and 1.0 ? While outside of the scope of this article, there appears to be some natural home field advantages that help the home team play well such as (1) familiarity with the field or court, (2) the home crowd energizing the home team, and (3) negligible travel weariness compared to what the visiting team faces. In some sports, the surface, size, and even shape of the court or field can be manipulated by the home team in order to improve the home field advantage.

For instance, in Major League Baseball (MLB), owners have been known to install artificial turf if their team is exceptionally fast or hits a lot of grounders and line drives because the turf (unlike grass) will not slow the ball down as much, allowing it to travel further into the outfield. The St. Louis Cardinals of the 1980 s were thought to have benefited from this because they were not a power hitting team, but did have a lot of fast runners in their line-up. Also, some home team groundskeepers would water down the area near first base when Rickey Henderson, the career leader in stolen bases in MLB, would arrive for a series of games against the home team, because it would hinder his ability to get a good jump and steal bases. This provides an advantage over homerun hitting teams. Similarly, the distance to the outfield fence can be brought in to produce many more homeruns or pushed further out to benefit a team with fast outfielders and batters who hit line drives, but not many homeruns. The Cleveland Indians purportedly pushed out their fence when they had the speedy center fielder Kenny Lofton. Fast teams in American football often like to play on artificial turf in order to accentuate their speed advantage. In the National Basketball Association (NBA), the court size and surface are essentially fixed by the league, preventing the home team from varying the home field/court advantage above and beyond the natural home field advantages listed above.

This research is an investigation of the ex ante optimal probability that a home team wins a game using data from the 2001-2002 NBA season. One result is an estimate of this optimal probability. The term "optimal" is based on the assumption that a team wants to maximize attendance at its home games, or that the maximization of attendance is a good proxy for the maximization of other objectives such as profits or revenues (or even wins). Késenne and Pauwels (2006) discuss how owner objectives tend to vary across leagues, continents, and even within leagues, and that real implications exist for talent demand, salaries, and competitive balance.

It has been shown that a team has a higher probability of winning a game when there are more of its fans in the stands (see Boyd \& Boyd, 1998). Thus, maximizing attendance might be optimal for a win-maximizing franchise owner. Similarly, attendance has often been used in the literature as a proxy for revenue with the understanding that ticket prices are set prior to the season. Therefore, given a certain level for ticket prices, a franchise ought to want to maximize attendance. Finally, the bulk of the costs for an NBA team are fixed, not variable. Profit maximization is, thus, aligned with revenue maximization. Overall, whether or not an individual owner is a win maximizer, profit maximizer, or combination of the two, drawing the largest crowds possible is almost certainly going to be aligned with those broader objectives. Moreover, Bollinger and Hotchkiss (2003) reason that profit maximization (or near profit maximization) is likely to be the most common objective in Major League Baseball, for instance.

However, the cost of creating a team that can win at home more than on the road might outweigh the net financial gain from the associated higher attendance, thus causing a divergence between attendance maximization and profit maximization. Disentangling that issue is beyond the scope of this research.

Other results of this study include the effect of Michael Jordan on demand, and an analysis of the diminishing effect of a previous season's performance on demand as the season progresses.

The rest of the paper is organized as follows. Section II provides a brief review of the literature on competitive balance and its effect on demand. The next section reviews the theory that predicts that the optimal probability should be between 0.5 and 1.0. Section IV describes the data and methodology used, while Section V shows the analysis and results. The final section concludes and discusses the importance of the findings. 


\section{Previous Literature}

In his article titled "Peculiar economics of professional sports," Neale (1964) first noted that competitors desired other quality competitors. Today, this notion of greater competition having a positive effect on a firm's bottom line is termed limited positive production network externality. Up to a point, more competitors are better than fewer, or higher quality competitors are better than lower quality competitors-a major exception to classical economic theory. In other words, higher revenues depend on increased on-the-field competition between teams. In order to achieve competitive games, league management have instituted numerous rules-starting in 1876 with the reserve system in baseball-to the current set of policies that include rookie drafts, salary caps, luxury taxes, and revenue sharing. Fort (2002) and Leeds and von Allmen (2002) discuss league rules for increasing competitive balance. The efficacy of these rules in increasing or maintaining competitive balance is currently under debate (see Fort \& Quirk, 1992; Sanderson, 2002; and Rascher, 2002, for different perspectives on this debate).

There have been dozens of studies performed on sport to determine how a variety of factors affect attendance or demand. In the early studies, Demmert (1973) and Noll (1974) found that absolute quality was in fact a significant determinant of attendance for baseball. More recently, Knowles, Sherony, and Haupert (1992) explain how uncertainty of outcome assumes that spectators increase their utility through sporting events that have a higher level of unpredictability, and that more evenly matched teams will yield less certain outcomes and thus, higher attendance. Some of the other demand factors analyzed include star players (Noll, 1974; Schurr, Wittig, Ruble, \& Ellen, 1987; Schwartz, 1973; Scully, 1974), game schedules (Hill, Madura, \& Zuber, 1982), and ticket prices (Bird, 1982; Boyd \& Boyd, 1998; Siegfried \& Eisenberg, 1980). Butler (2002) includes a recent bibliography of studies of the determinants of demand for sporting events. Using a sample of 1988 Major League Baseball games, Knowles et al. (1992) found that the ex ante attendance maximizing probability that the home team would win a game is about 0.60. Rascher (1999) used data for the entire 1996 MLB season and concluded that the ex ante optimal probability that the home team would win was between 0.60 and 0.67 , depending on the specification.

\section{Theory}

The theory being tested in this article is based on the sports league model developed by Rascher (1997). It contains both absolute and relative quality of play and competition as factors of demand. The model directly shows that the ex ante optimal probability that the home team wins a game is between 0.5 and 1.0. The empirical analysis that follows will help determine where the optimal probability will fall within that range.

The demand function takes the form

$$
Q_{h}=S_{i}\left(A T_{i}+B T_{j}+C\left(T_{i}-T_{j}\right)^{2}+\text { other }\right),
$$

with the restriction that $A>B>0>C . T_{i}$ is the talent level of team $i$, while $T_{j}$ is the talent level of team $j . Q_{h}$ is the demand for home games. $A$ is the marginal propensity to attend home games with respect to the home team's quality. $B$ is the marginal propensity to attend home games with respect to the visiting team's quality, and is assumed to be less important than home team quality to the hometown fans. $C$ is the marginal propensity to attend home games that is attributable to the uncertainty of the contest outcome. The more divergent the talent levels of the two teams, the lower the demand. $S_{i}$ is a scalar that controls for the potential demand from market size, income, ticket prices, and other factors that vary across cities and over time. The restrictions on $A, B$, and $C$ show that demand is maximized with respect to the home team's talent $\left(T_{i}\right)$, by finding the maximum of the quadratic equation nested within the demand curve. The result is that $Q_{h}$ is maximized when $T_{i}=T_{j}-(A / 2 C)$. Given that talent is not measured directly, winning percentage is a monotonic function of talent. Similarly, in order to determine the probability that the home team wins a particular game $\left(P_{h}\right)$, the current winning percentage of the home team $\left(w_{i}\right.$; at home and on the road) and visiting team $\left(w_{j}\right)$ can be used to create a monotonic function of the home team's winning percentage:

$$
P_{h}=\frac{\left(1-w_{j}\right) w_{i}}{w_{i}\left(1-w_{j}\right)+w_{j}\left(1-w_{i}\right)} .
$$

Hence, winning percentage is a proxy for talent and can be turned into a probability formula. The Appendix con- 
tains a derivation of the probability function. The empiri$\mathrm{cal}$ analysis will use a quadratic of the probability function, not talent, which cannot effectively be measured.

The hypotheses being tested are: (1) the absolute quality of the two teams is an important determinant of demand ( $A$ and $B$ are both positive and significant), (2) home town fans are more sensitive to changes in the home team's talent level than to changes in the visiting team's talent level $(A>B)$, and (3) fans want to see games where the outcome is uncertain ( $C<0$ and significant). Additionally, a direct estimate of the optimal (from the league's perspective) ex ante probability that the home team wins a particular game will be generated.

\section{Data and Methodology}

The data includes information regarding each NBA game for the 2001-2002 regular season. There are 25 variables for each of the 1,189 observations (based on $29 \mathrm{NBA}$ teams playing 82 games each).

\section{Dependent Variables}

Two different variables are used to define demand for each data set. One, a binary variable, "sell-out," translates to a measure of the probability that there was an occurrence of a sell-out or near sell-out (greater than $95 \%$ of the capacity sold out). The second dependent variable is attendance.

Sell-outs, according to the definition used in this study, occurred 446 times over the entire regular season. Attendance ranged from 5,234 to 35,052 with a mean of 16,975 and a standard deviation of 3,598 . Table 1 provides a summary of the data.

\section{Time-Constant Independent Variables}

Certain factors of demand are constant over time, but vary across teams. Population is a typical factor of demand for sporting events. The population of the Consolidated Metropolitan Statistical Area (CMSA), measured in millions, is used in this analysis and is expected to have a positive effect on attendance. Median household income and the unemployment rate are also included as potential determinants of demand. The expected effect of income is positive and unemployment negative, if NBA games are, in fact, normal goods. The percentage of the local population that is not white has historically been found to be negatively associated with NBA attendance. Noll (1974), Kahn and Sherer (1988), and Kanazawa and Funk (2001) each found a negative correlation between the racial characteristics of the local population and attendance at NBA games.

As with any demand function, ticket price is expected to have a negative effect on attendance. Most previous research, however, has not found a strong link between ticket price and demand (Fort \& Quirk, 1992; Fort, 2005). However, Coates and Harrison, (2005) using instrumental variables estimation (IV) on a number of different ticket price definitions, find inelastic pricing that was statistically significant for MLB. The variation in ticket price in their analysis was across teams and over a number of years. In this study of NBA teams, the ticket price variable is constant for each game and only varies across teams; thus, IV estimation is not applicable.

Average ticket price is included in the analysis to capture the cost of attending an NBA game. In 2001-02 it ranged from $\$ 26.38$ (Golden State Warriors) up to $\$ 65.95$ (New York Knicks), with an average of \$41.91. The full cost of attending a basketball game includes much more than just the ticket price. The Fan Cost Index ${ }^{T M}$ (FCI) includes the cost of concessions, parking, and some merchandise. It ranges from US $\$ 175.35$ (Toronto Raptors) to $\$ 357.90$ (New York Knicks) with a league average of $\$ 244.44$.

Lastly, home and visiting team previous season records are included. These records are measured using home and visiting season wins, which ranged from 15 to 58 with a mean of 41 and a binary variable to denote if the home and/or visiting team made the playoff in the previous season. These two variables are expected to have a positive effect on attendance because season ticket decisions are often based on previous season's quality, given that is the bulk of the information available on expected team performance.

\section{Time-Varying Independent Variables}

The determinants of demand that vary from game to game are grouped into player quality, team quality, and the context of the game. The NBA promotes individual players relatively more than other sports leagues, which focus on marketing the teams themselves. The star player 
Rascher, Solmes

Table 1: 2001-2002 National Basketball Association Game-by-Game Statistics.

\section{Dependent Variable:}

Attendance

Whether a Game was Sold Out

Time-Constant Variables:

Number of Home Team Previous Season Wins

Home Team Previous Season Playoff Team

Fan Cost Index (FCI)

Ticket Price (as reported in FCI)

Median Household Income in CMSA

Percentage Non-white in CMSA

Population of CMSA (In Millions)

Unemployment Rate of CMSA

Stadium Seating

Game-by-Game Variables:

Estimated Probability the Home Team Will Win

Home Win/Loss Percentage

Visitor Win/Loss Percentage

Average Difference in Win Percentages

Home Win Percentage in Last Ten Games

Visitor Win Percentage in Last Ten Games

Number of All-Stars Playing

Michael Jordan Playing in Game

Scoring Leaders Playing

Rebounding Leaders Playing

Assist Leaders Playing

Number of Defensive Team Members Playing

Game is on a Weekend

Home Opener

Visiting Team Previous Season Number of Wins

Visiting Team Previous Season Playoff Team

\section{Minimum}

5,234

0

15

0

175.35

$\$ 26.38$

$\$ 26,543$

0.035

0.36

0.005

16,285
Mean

16,975

0.38

41

0.59

244.35

$\$ 41.91$

$\$ 45,655$

0.33

3.52

0.06

19,670

0.50

0.49

0.49

0.18

0.49

0.50

1.62

0.05

0.63

0.62

0.60

0.67

0.30

0.02

41

0.59
Maximum

35,052

\section{1}

58

1

357.9

$\$ 65.95$

$\$ 61,466$

0.717

16.3

0.098

22,879

\section{Notes:}

(1) There are 1,189 observations.

(2) The data is for the regular season only.

(3) The data is from www.sfo.com/ csuppes/NBA/index.htm, www.nba.com, U.S. Census, Statistics Canada, and Team Marketing Report.

(4) The All-Star category is based on whether the player was in the All-Star game during the 2001-2002 season. The scoring, rebounding, and assist leader variables are based on the final tally at the end of the season, but clearly indicates the leaders at the time. The defensive players were those who made the 1st Team NBA All-Defensive Team during the 2001-2002 season. 
attributes consist of factors measuring the number of AllStar team members, the number of Top 10 scoring leaders, rebounding leaders, and assist leaders, and the number of top defensive players in each game. Each of these is expected to have a positive affect on attendance.

A separate indicator variable is used for games in which Michael Jordan appears. His impact is expected to be greater than that of simply an All-Star player. Hausman and Leonard (1997) estimated that Michael Jordan generated approximately $\$ 53$ million in incremental attendance and merchandise revenues for all of the other teams in the NBA for the 1991-92 season. Their findings do not include revenue generated for his team or any other revenue streams for any teams, such as media revenues or concessions sales. Home opening game and weekend game (Saturday and Sunday) indicator variables are included as factors of demand. The home opener satisfies the pent-up demand from the off-season. Fans presumably have more time available to attend weekend games. Other research on baseball has shown the significant impact of opening day and weekend games. A weekend Major League Baseball game has a 25\% higher attendance, ceteris paribus (Rascher, 1999).

The key variables of interest are those that account for absolute and relative team quality. The home team's current winning percentage and the visiting team's current winning percentage are utilized to create a number of variables: the difference between the home and visiting team's winning percentages, the probability that the home team wins a game, and the probability squared. ${ }^{1}$ As described above, these will allow for the estimation of the optimal probability that the home team wins.

\section{Analysis and Results}

There are three models examined in this analysis. The first model tests whether $A>B>0>C$, which would show that an important set of assumptions in the competitive balance model are true. Again, the assumptions are that the attendees care about the absolute quality of teams on the field $(A>0$ and $B>0)$, they care about close contests or relative quality $(0>C)$, and they care more about the home team's quality than the visiting team's quality $(A>$ $B)$. The second model directly estimates the ex ante opti- mal probability that the home team wins the game. The third model also estimates the same probability, but uses an indicator variable of whether a game was nearly sold out instead of attendance as the measure of demand. Using the percentage of capacity sold out is one way to account for the truncation of the attendance variable. The number of truncated games is significant. During the 2001-2002 season, approximately $37 \%$ of games recorded capacity sold out of greater than $95 \%$. Another way to account for truncation of the dependent variable is to use a censored regression (similar to a tobit) that effectively estimates what attendance would be if there were not a capacity issue.

The first model is estimated using a censored regression that accounts for the occasional truncation of the dependent variable, attendance. Sensitivity analyses show that multicollinearity exists across the various measures of winning (winning percentage, last ten games winning percentage, previous season winning percentage, previous season playoffs). Thus, the final analysis removed the winning percentage over the last ten games variable and the previous season playoffs variable. As expected, serial correlation is not a problem, given that the data spans less than one year. The data are distributed approximately normal except for the dummy variables, which is typical. Further, the errors have been adjusted for heteroscedasticity.

The second model uses the same estimation methods as the first model. However, multicollinearity is not an issue because there is only one measure of winning for the home and visiting teams- the probability that each team wins (see Appendix for a derivation).

The dependent variable in the third model is a dummy variable that equals 1 for games in which attendance is at least $95 \%$ of capacity, and 0 otherwise. A probit analysis is used to estimate this model. This model is included for comprehensiveness, and specifically, as another way to account for the problem of sell-outs. However, as with all dummy variables, the dependent variable is a cruder measure of something else, attendance.

A second set of analyses is prepared to provide more meaning for some of the independent variables. For instance, the home team winning percentage near the beginning of the season is very erratic because there are not many games in the denominator of the calculation. 
Rascher, Solmes

Table 2: Regression Results: Full Season

\begin{tabular}{|c|c|c|c|}
\hline Model: & $\mathrm{A}>\mathrm{B}>0>\mathrm{C}$ & Probability Model & Sell-out Model \\
\hline Adjusted R-Squared or Pseudo R-Squared & 0.41 & 0.31 & 0.14 \\
\hline F-Value or Likelihood Ratio Chi-Squared & 35.92 & 34.34 & 226.61 \\
\hline Number of Observations & 1189 & 1189 & 1189 \\
\hline Optimal Probability Home Team Wins & -- & 0.67 & 0.66 \\
\hline \multicolumn{4}{|l|}{ Independent Variables: } \\
\hline \multirow[t]{2}{*}{ Constant } & $-3353.01^{* * *}$ & & \\
\hline & $(-6.53)$ & -- & -- \\
\hline \multirow[t]{2}{*}{ Home Team Win/Loss Percentage } & $7424.61^{* * *}$ & & \\
\hline & $(3.69)$ & -- & -- \\
\hline \multirow[t]{2}{*}{ Home Team Win/Loss Percentage Squared } & $-4875.14^{* * *}$ & & \\
\hline & $(-2.55)$ & --- & -- \\
\hline \multirow[t]{2}{*}{ Visiting Team Win/Loss Percentage } & 3507.10 & & \\
\hline & $(1.07)$ & -- & -- \\
\hline \multirow[t]{2}{*}{ Visiting Team Win/Loss Percentage Squared } & -2062.50 & & \\
\hline & $(-0.99)$ &.-- & --- \\
\hline \multirow[t]{2}{*}{ Difference in Win/Loss Percentages } & 381.93 & & \\
\hline & $(0.57)$ & --- & -- \\
\hline \multirow[t]{2}{*}{ Difference in Win/Loss Percentages Squared } & -344.19 & & \\
\hline & $(-0.49)$ & -- & -- \\
\hline \multirow[t]{2}{*}{ Probability Home Team Wins } & --- & $11340.87^{* * *}$ & $3.39^{*}$ \\
\hline & & $(2.73)$ & $(1.65)$ \\
\hline \multirow[t]{2}{*}{ Probability Home Team Wins Squared } & --- & $-8500.70^{* *}$ & -2.55 \\
\hline & & $(-2.05)$ & $(-1.25)$ \\
\hline \multirow[t]{2}{*}{ Home Team Previous Season Wins } & $93.29 * * *$ & & \\
\hline & $(6.21)$ & --- & -- \\
\hline \multirow[t]{2}{*}{ Visiting Team Previous Season Wins } & 5.68 & & \\
\hline & $(0.48)$ & --- & -- \\
\hline \multirow[t]{2}{*}{ Michael Jordan } & $4235.76^{* * *}$ & $2290.80^{* * *}$ & $2.32^{* * *}$ \\
\hline & $(9.89)$ & $(5.82)$ & $(6.76)$ \\
\hline \multirow[t]{2}{*}{ All-Star Team Members (2001-02 Season) } & 72.12 & $518.72^{* * *}$ & $0.15^{* * *}$ \\
\hline & $(0.71)$ & $(5.12)$ & $(3.31)$ \\
\hline \multirow[t]{2}{*}{ Assist Leaders (Top 10, 2001-02 Season) } & $-792.23^{* * *}$ & $-723.39 * * *$ & -0.070 \\
\hline & $(-6.06)$ & $(-5.11)$ & $(-1.08)$ \\
\hline \multirow[t]{2}{*}{ Defensive Team Members (2001-02 Season) } & $323.13^{* * *}$ & $552.44^{* * *}$ & $0.18^{* * *}$ \\
\hline & $(2.61)$ & $(4.66)$ & $(3.42)$ \\
\hline \multirow[t]{2}{*}{ Weekend Game } & $872.15^{* * *}$ & $767.78^{* * *}$ & $0.35^{* * *}$ \\
\hline & $(4.93)$ & (3.99) & $(4.08)$ \\
\hline \multirow[t]{2}{*}{ Fan Cost Index ${ }^{\mathrm{TM}}(\mathrm{FCI})$} & -1.87 & $5.72^{* * *}$ & 0.00086 \\
\hline & $(-0.87)$ & (3.99) & $(0.88)$ \\
\hline \multirow[t]{2}{*}{ Median Household Income in Local CMSA } & $0.033^{* *}$ & $-0.048^{* * *}$ & $-0.000018^{* * *}$ \\
\hline & $(2.30)$ & $(-3.62)$ & $(-2.75)$ \\
\hline \multirow[t]{2}{*}{ Non-White Percentage in Local CMSA } & -10.17 & $-16.35^{\star *}$ & -0.053 \\
\hline & $(-1.34)$ & $(-1.98)$ & $(-0.15)$ \\
\hline \multirow[t]{2}{*}{ Population of Local CMSA (in Millions) } & $118.60^{* * *}$ & $65.53^{* * *}$ & -0.0091 \\
\hline & $(4.83)$ & $(2.51)$ & $(-0.79)$ \\
\hline \multirow[t]{2}{*}{ Unemployment Rate in Local CMSA (\%) } & $44491.05^{* * *}$ & $26728.90^{* * *}$ & -0.48 \\
\hline & $(6.72)$ & $(3.91)$ & $(-0.14)$ \\
\hline
\end{tabular}

T-statistics are in parentheses. Significance: ${ }^{*}-10 \%$ level; ${ }^{* *}-5 \%$ level; ${ }^{\star * *}-1 \%$ level. 
This is also true for all of the other winning-related variables. The second analyses use data after approximately $36 \%$ of the season has been played (from January 2002 to the end of the regular season).

The results for all three models using the full season of data are shown in Table 2. As the competitive balance theory predicts, the home team's winning percentage effect was found to be positive, but greater than the visiting team's winning percentage effect $(A>B>0)$, showing that fans respond relatively more to changes in their home team's quality than that of the visiting team. Further, the squared difference in winning percentages has a negative impact on attendance, implying that fans care about close contests, all else equal $(C<0)$.

The probability model generates an estimate of the optimal ex ante probability that the home team wins a game. The inclusion of the variable "Probability Home Team Wins" (PROB) and its squared term in the equation in Table 2 creates a quadratic relationship between Attendance and $P R O B$. The attendance maximizing solution to this equation,

$$
\text { Attendance }=f\left(a P R O B+b P R O B^{2}\right) \text {, }
$$

is $P R O B=-a /(2 b)$. Demand is maximized when this probability is about $67 \%$ (i.e., $-a /(2 b)=-11,340 /\left(2^{\star}(-\right.$ $8,500))=67 \%$ ), or when the home team has twice the chance as the visiting team to win the basketball game. Likewise, the Sell-out Model, using the indicator variable as the dependent variable, finds a similar optimal probability of $66 \%$.

There are a number of other interesting findings. The average change in attendance from an increase in home team quality shows that obtaining one more win during the middle of the season (21-21 record to 22-20; a 0.02381 increase in winning percentage) leads to an increase in attendance of about 177 fans per game. This is a gain of over $1 \%$ per game for each extra win. While NBA attendance varies much less than many other sports, the weekend effect was still relatively large at approximately 800 additional attendees per game (an increase of nearly $5 \%$ per game).

Michael Jordan was one of the most demand-inducing team-sport athletes in North America during the time period. All 56 games in which he appeared in 2001-2002 were sell-outs. His team, the Washington Wizards, sold out each of its 41 home games, including 10 games in which Jordan did not play. For a few teams, the home games against Jordan and his team were one of only a few that sold out. ${ }^{2}$ On the other hand, there were some teams that sold out many games with Jordan playing in either one or none of them (e.g., New York Knicks, Sacramento Kings, and Dallas Mavericks).

This analysis provides evidence in support of that argument. When comparing individual player effects, Michael Jordan draws more fans than the equivalent of four AllStars or defensive team members. Based on the findings in Table 2 and Table 3, Michael Jordan drew about 3,000 more fans per game than would otherwise be the case. That is an increase of about $18 \%$. That is likely to be a conservative estimate, given that each game he played in sold out. In other words, the true demand for his games was likely higher than the capacity at the basketball arena in which the game took place.

There were multicollinearity problems with scoring leaders, rebounding leaders, and number of All-Stars playing in the game. The final model chosen excluded scoring leaders and rebounding leaders in favor of the number of All-Stars.

The analysis based on the latter two-thirds of the season provides some expected results. The goodness-of-fit is higher, most likely because the winning-related variables are more stable and meaningful than for the entire season. As a season progresses, the impact of the results of the previous season on demand are expected to diminish. The effect of the home team's previous season is smaller than it is for the entire season, dropping from 93 fans per game for each additional win during the prior season to 77 .

\section{Conclusion and Discussion}

Fans desire games in which the home team is expected to win, but not with certainty. In the early years of professional basketball, regional leagues would form and exist until one team dominated the circuit and the league faltered (Neft \& Cohen, 1991). Fans did not want certainty in the games, but wanted true contests where the outcomes were uncertain. Today the concept of competitive balance is as important as it was a century ago. Leagues create rules in order to promote and maintain a desired 
Rascher, Solmes

Table 3: Regression Results: January Through the End of the Season.

\begin{tabular}{|c|c|c|c|}
\hline Model: & $\mathrm{A}>\mathrm{B}>0>\mathrm{C}$ & Probability Model & Sell-out Model \\
\hline Adjusted R-Squared or Pseudo R-Squared & 0.44 & 0.37 & 0.14 \\
\hline F-Value or Likelihood Ratio Chi-Squared & 24.81 & 30.5 & 148.05 \\
\hline Number of Observations & 757 & 757 & 757 \\
\hline Optimal Probability Home Team Wins & $\cdots$ & 0.60 & 0.61 \\
\hline \multicolumn{4}{|l|}{ Independent Variables: } \\
\hline \multirow[t]{2}{*}{ Constant } & $-12490.86^{* * *}$ & & \\
\hline & $(-3.76)$ & --- & --- \\
\hline \multirow[t]{2}{*}{ Home Team Win/Loss Percentage } & 4751.80 & & \\
\hline & $(0.85)$ & --- & --- \\
\hline \multirow[t]{2}{*}{ Home Team Win/Loss Percentage Squared } & 2989.54 & & \\
\hline & $(0.54)$ & --- & --- \\
\hline \multirow[t]{2}{*}{ Visiting Team Win/Loss Percentage } & 2792.41 & & \\
\hline & $(0.56)$ & --- & -- \\
\hline \multirow[t]{2}{*}{ Visiting Team Win/Loss Percentage Squared } & 2946.57 & & \\
\hline & $(0.57)$ & --- & --- \\
\hline \multirow[t]{2}{*}{ Difference in Win/Loss Percentages } & -259.72 & & \\
\hline & $(-0.15)$ & -- & --- \\
\hline \multirow[t]{2}{*}{ Difference in Win/Loss Percentages Squared } & -1332.40 & & \\
\hline & $(-0.78)$ & --- & --- \\
\hline \multirow[t]{2}{*}{ Probability Home Team Wins } & --- & $35418.28^{* * *}$ & $11.92^{*}$ \\
\hline & & $(2.53)$ & $(1.79)$ \\
\hline \multirow[t]{2}{*}{ Probability Home Team Wins Squared } & --- & $-29652.20^{* *}$ & -9.77 \\
\hline & & $(-2.14)$ & $(-1.48)$ \\
\hline \multirow[t]{2}{*}{ Home Team Previous Season Wins } & $77.45^{* * *}$ & & \\
\hline & $(3.65)$ & --- & -- \\
\hline \multirow[t]{2}{*}{ Visiting Team Previous Season Wins } & 14.96 & & \\
\hline & $(0.96)$ & --- & --- \\
\hline \multirow[t]{2}{*}{ Michael Jordan } & $3700.02^{* * *}$ & $3086.40^{* * *}$ & $2.038^{* * *}$ \\
\hline & $(5.84)$ & $(4.87)$ & (4.46) \\
\hline \multirow[t]{2}{*}{ All-Star Team Members (2001-02 Season) } & $-325.14^{* *}$ & & \\
\hline & $(-2.27)$ & -- & --- \\
\hline \multirow[t]{2}{*}{ Assist Leaders (Top 10, 2001-02 Season) } & $-705.69^{* * *}$ & $-537.003^{* * *}$ & $-0.0028^{* * *}$ \\
\hline & $(-4.26)$ & $(-3.18)$ & $(-4.46)$ \\
\hline \multirow[t]{2}{*}{ Defensive Team Members (2001-02 Season) } & 23.55 & 308.24 & 0.094 \\
\hline & $(0.14)$ & $(2.02)$ & $(1.35)$ \\
\hline \multirow[t]{2}{*}{ Weekend Game } & $1141.53^{* * *}$ & $1131.72^{\star * *}$ & $0.45^{* * *}$ \\
\hline & $(5.23)$ & $(4.91)$ & $(4.14)$ \\
\hline \multirow[t]{2}{*}{ Fan Cost IndexTM (FCI) } & -1.81 & 1.50 & -0.00050 \\
\hline & $(-0.67)$ & $(0.55)$ & $(-0.40)$ \\
\hline \multirow[t]{2}{*}{ Median Household Income in Local CMSA } & 0.027 & $-0.043^{* * *}$ & -0.000012 \\
\hline & $(1.35)$ & $(-2.63)$ & $(-1.51)$ \\
\hline \multirow[t]{2}{*}{ Non-White Percentage in Local CMSA } & -1042.57 & $-5127.20^{* * *}$ & 0.19 \\
\hline & $(-0.97)$ & $(-5.49)$ & $(0.41)$ \\
\hline \multirow[t]{2}{*}{ Population of Local CMSA (in Millions) } & $120.70^{* * *}$ & $102.46^{* * *}$ & 0.0063 \\
\hline & (3.75) & (3.08) & $(0.43)$ \\
\hline \multirow[t]{2}{*}{ Unemployment Rate in Local CMSA (\%) } & $38437.53^{* * *}$ & $37890.74^{* * *}$ & -1.14 \\
\hline & $(4.84)$ & $(4.74)$ & $(-0.28)$ \\
\hline
\end{tabular}

T-statistics are in parentheses. Significance: ${ }^{*}-10 \%$ level; ${ }^{* *}-5 \%$ level; ${ }^{\star * *}-1 \%$ level. 
level of competitive balance. However, individual teams try to create a home court advantage that allows them to win more often at home. A consequence of this is that, in equilibrium, they will lose more games on the road (because of similar measures by opposing teams), thereby not disturbing overall competitive balance (as measured by the dispersion of wins across teams throughout the season), but rather, distributing the wins to occur more often at home.

This paper estimated the optimal ex ante probability that the home team would win a game for the National Basketball Association during the 2001-02 season. Team winning percentages were turned into probabilities of winning and, along with other control variables, were analyzed to determine their effect on demand. The $e x$ ante optimal probability that the home team would win was calculated to be about $66 \%$ for the full season and about $60 \%$ for the last 757 games. ${ }^{3}$ Findings for baseball concluded that the optimal probability was about $70 \%$. Economic theory would actually predict the opposite, but only slightly. The shorter the season, the more dominant a team has to be in order to ensure success (e.g., making the playoffs) because one bad game has more impact on success. If fans understand this, then they would want the home team to win with more certainty for a sport with a shorter season, such as basketball, than for a sport with a longer season, such as baseball. It becomes apparent that when basketball fans are assumed to be rational consumers, they are slightly more concerned with seeing competitive games than with seeing their team have certain success.

Another analysis was performed to test a theoretical demand model whose main features are (1) local fans want the home team to be of high quality, (2) fans want the visiting team to also be of high quality, although it is less important than that for the home team, and (3) fans want the outcome of the contest to be uncertain, not predetermined. The results supported the theoretical model.

A question was placed on the cover of Sports Illustrated on March 10 $0^{\text {th }}, 1997$ : "Are the Bulls so good they're bad for the NBA?" In theory the answer is "Yes." The Bulls had a record of 69-13 in the 1996-97 season on their way to another championship. However, the Bulls sold out all of their games that season anyway because of absolute quality of play and a desire to see the spectacle of Michael Jordan and company play. If that dominance were to have continued for years, it could have led the NBA to become dull and pre-determined. The positive effect on demand of a star player dominating a sport compared with the negative effect of the loss of uncertainty of outcome is not fully understood. It appears that the star effect is larger than the uncertainty of outcome effect, but that might not be the case if the particular star effect were to continue unabated for a long period of time, and thus, cause games and seasons to become predictable.

There is some current evidence of this in certain soccer leagues in Europe where a few teams with star players dominate each season (see Lago, Simmons, \& Szymanski, 2006), causing the fans of the second tier clubs to lost interest, and historically in MLB when the New York Yankees dominated baseball in the 1920 s and saw declines in attendance at home games and for other teams in the league. Similarly, the original American Basketball League (in the 1920s) suffered because of competitive imbalance issues. Recent research by Paul and Weinbach (2007) shows that the expected uncertainty of outcome is an important determinant in the number of fans watching National Football League games on television.

As discussed above, these findings help focus a league on the amount of home court advantage that it should want each team to have. How can teams improve home court advantage? There is a belief that one aspect of home court advantage is the crowd providing emotional energy to the home team players and well-placed noise to disrupt the opponent. Research shows that sporting events with higher attendances improve the chances of the home team winning the game (Boyd \& Boyd, 1998; Liu, Li, Wang, \& Liu, 2002). One source of home court advantage is familiarity with the playing surface and lighting (St. John, 2003). Another source of home court advantage is the noise created by the home team's sound system (Bailey, 2001). A commonly discussed source that a home team does not have control over is the wear on the body from travel. Also, referees are often accused of making calls to benefit the home team. Some believe that various leagues support this in order to satisfy the home team crowds, but no recent concrete evidence of this has been found for major North American sports leagues. 
An important area of future research is to determine how to change home court advantage and the effects of each method so leagues can determine how much leniency to give. In baseball, the home team can change the size of the field to fit its talent, but not in basketball. Also, what are the findings for sports outside of North America, and if they are significantly different, then why?

\section{References}

Bailey, L. (2001, February 8). Five roads to redemption. Gauntlet: Undergraduate Students' Newsweekly, Retrieved July 5, 2003, from http://gauntlet.ucalgary.ca/story/2517

Bird, P. J. (1982). The demand for league football. Applied Economics, 14, 637-649.

Bollinger, C., \& Hotchkiss, J. (2003). The upside potential of hiring risky workers: Evidence from the baseball industry. Journal of Labor Economics, 21(4), 923-44.

Boyd, D. W., \& Boyd, L. A. (1998). The home field advantage: Implications for the pricing of tickets to professional team sporting events. Journal of Economics and Finance, 22(2-3), 169-79.

Butler, M. R. (2002). Interleague play and baseball attendance. Journal of Sports Economics, 3(4), 320-34.

Demmert, H. G. (1973). The economics of professional sports. Lexington, MA.: Lexington Books.

Fort, R. D. (2002). Sports economics. Upper Saddle River, NJ: Prentice Hall.

Fort, R. D. (2005). Inelastic sports pricing. Managerial and Decision Economics, 25(2), 87-94.

Fort, R. D., \& Quirk, J. (1992). Pay dirt: The business of professional team sport. Princeton, NJ: Princeton University Press.

Fort, R. D., \& Quirk, J. (1995). Cross-subsidization, incentives, and outcomes in professional team sports leagues. Journal of Economic Literature, 33, 1265-1299.

Hausman, G. K., \& Leonard, J. A. (1997). Superstars in the National Basketball Association: Economic value and policy. Journal of Labor Economics, 15(5), 586-624.

Hill, J. R., Madura, H., \& Zuber, R. A. (1982). The short run demand for Major League Baseball. Atlantic Economic Journal, 31(2), 31-35.

Kahn, L. M., \& Sherer, P. D. (1988). Racial differences in professional basketball players' compensation. Journal of Labor Economics, $6,40-61$.

Kanazawa, M. T., \& Funk, J. P. (2001). Racial ciscrimination in professional basketball: Evidence from Nielsen Ratings. Economic Inquiry, 39(4), 599-608.

Késenne, S., \& Pauwels, W. (2006). Club objectives and ticket pricing in professional team sports. Eastern Economic Journal, 32(3), 549-560.

Knowles, G., Sherony, K., \& Haupert, M. (1992). The demand for Major League Baseball: A test of the uncertainty of outcome hypothesis. The American Economist, 36(2), 72-80,

Lago, U., Simmons, R., \& Szymanski, S. (2006). The financial crisis in European football: An introduction. Journal of Sports Economics, 7(1), 3-12.

Leeds, M., \& von Allmen, P. (2002). The economics of sports. Boston, MA: Addison-Wesley.

Liu, J. K., Li, Z. G., Wang, X. F., \& Liu, Y. W. (2002). Study on the home court advantage in the CBA. Journal of Physical Education, 9(1), 117-119.
Neale, W. C. (1964). The peculiar economics of professional sports: A contribution to the theory of the firm in sporting competition and market competition. The Quarterly Journal of Economics, 78(1), 1-14.

Neft, D. S., \& Cohen, R. M. (1991). The sports encyclopedia: Pro basketball ( $4^{\text {th }}$ ed.). New York, NY: St. Martin's Press.

Noll, R. G. (1974). Attendance and price setting. In R. G. Noll (Ed.), Government and the sports business (pp. 115-158). Washington DC: The Brookings Institution.

Paul, R., \& Weinbach, A. (2007). The uncertainty of outcome and scoring effects on Nielsen Ratings for Monday Night Football. Journal of Economics and Business, 59(3), 199-211.

Rascher, D. A. (1997). A model of a professional sports league. In W. Hendricks (Ed.), Advances in the economics of sport, Vol. 2. (pp. 27-76). Greenwich, CT: JAI Press.

Rascher, D. A. (1999). The optimal distribution of talent in Major League Baseball. In L. Hadley, E. Gustafson, \& J. Fizel (Eds.), Sports economics: Current research (pp. 27-45). Westport, CT: Praeger Press.

Rascher, D. A. (2002). Competitive balance on the field and in the courts. For the Record, 13(2), 3-6.

Sanderson, A. R. (2002). The many dimensions of competitive balance. Journal of Sports Economics, 3(2), 204-228.

Schurr, K. T., Wittig, A. F., Ruble, V. E., \& Ellen, A. S. (1987). Demographic and personality characteristics associated with persistent, occasional, and non-attendance of university male basketball games by college students. Journal of Sport Behavior, 11(1), 3-17.

Schwartz, J. M. (1973). Causes and effects of spectator sports. International Review of Sport Sociology, 34(8), 25-45.

Scully, G. W. (1974). Pay and performance in Major League Baseball. American Economic Review, 64(6), 917-930.

Siegfried, J., \& Eisenberg, J. (1980). The demand for minor league baseball. Atlantic Economic Journal, 29, 59-69.

St.. John, A. (2003, May 9). By the numbers: Home sweat home. Wall Street Journal, p. W4.

\section{Endnotes}

'To be clear, the home team's current winning percentage is the winning percentage of the home team for a specific game prior to the start of the game. It is not a reflection of the percentage of home games a team has won up to that point.

${ }^{2}$ One of the two sellouts for the Charlotte Hornets, one of the four sellouts for the Chicago Bulls (Jordan's former team), one of the three sellouts for the Cleveland Cavaliers, one of the three sellouts for the Houston Rockets, and two of the three sellouts for the Miami Heat were games against Jordan and his teammates.

${ }^{3}$ It should be noted that this is an average across each NBA team and it is likely that the optimal probability varies across teams. 


\section{Appendix}

This shows the derivation of the probability that the home team will win a particular game based on winning percentages (Fort \& Quirk, 1995).

If $T_{i}$ and $T_{j}$ are the playing strengths of team $\mathrm{i}$ and $\mathrm{j}$, then the probability that team $\mathrm{i}$ beats team $\mathrm{j}$ is

$$
\operatorname{Prob}(i \text { beats } j)=\frac{T_{i}}{T_{i}+T_{j}} .
$$

The expected winning percentage of team $i$ when playing an average team is

$$
w_{i}=\frac{T_{i}}{T_{i}+\frac{n \bar{T}-T_{i}}{n-1}}
$$

where $\bar{T}$ is the average strength of each team in the league, and $n$ is the number of teams in the league. Solving equations (4) and (5) for $T_{i}$ and $T_{j}$ leads to

$$
T_{i}=\frac{n \bar{T} w_{i}}{(n-1)-(n-2) w_{i}},
$$

and

$$
T_{j}=\frac{n \bar{T} w_{j}}{(n-1)-(n-2) w_{j}} .
$$

Plugging back into equation (4) and letting $n$ go to infinity yields the probability equation based on winning percentages

$$
P_{h}=\frac{\left(1-w_{j}\right) w_{i}}{w_{i}\left(1-w_{j}\right)+w_{j}\left(1-w_{i}\right)} .
$$




\section{COPYRIGHT INFORMATION}

TITLE: Do Fans Want Close Contests? A Test of the Uncertainty of Outcome Hypothesis in the National Basketball Association

SOURCE: Int J Sport Financ 2 no3 Ag 2007

The magazine publisher is the copyright holder of this article and it is reproduced with permission. Further reproduction of this article in violation of the copyright is prohibited. To contact the publisher: http://www.fitinfotech.com/IJSF/IJSF.tpl 